\title{
Behavioral studies of surge protection components
}

\author{
Teik Hua Kuan, Kuew Wai Chew, Kein Huat Chua \\ Department of Electrical and Electronic Engineering, Universiti Tunku Abdul Rahman, Malaysia
}

\begin{tabular}{|c|c|}
\hline Article Info & ABSTRACT \\
\hline Article history: & In our daily life, almost all the items we used, being a computer, television, \\
\hline Received Apr 6, 2020 & lift or vehicle we drive consist of some kind of electrical or electronics \\
\hline Revised Jun 3, 2020 & by lightning activity or electrical switching events, as there are more than \\
\hline Accepted Aug 20, 2020 & $\begin{array}{l}2000 \text { thunderstorms in progress at any time resulting in } 100 \text { lightning flashes } \\
\text { to ground per second. In practice, any device using electricity will subject to }\end{array}$ \\
\hline Keywords: & $\begin{array}{l}\text { surge damages induced from the lightning or switching of heavy load. Surge } \\
\text { protection device (SPD) is added at the power distribution panel and critical }\end{array}$ \\
\hline Gas discharge tube & process loop to prevent damage subsequently cause plant shutdown. There \\
\hline Lightning protection & $\begin{array}{l}\text { are many questions raised on the SPD. How can this small device protect } \\
\text { the equipment from large energy release by the lightning? What is inside }\end{array}$ \\
\hline Metal oxide varistor & the device? How does it work? This paper provides comprehensive detail in \\
\hline Surge avalanche diode & revealing the science and engineering behind the SPD, its individual \\
\hline Surge protection component & component characteristic and how does it work. The technical information \\
\hline Thyristor surge protection & $\begin{array}{l}\text { presented is limited to surge protection on equipment; surge protection for } \\
\text { building structure will not be discussed here. }\end{array}$ \\
\hline
\end{tabular}

This is an open access article under the CC BY-SA license.

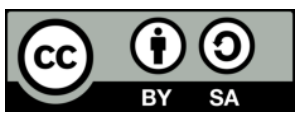

\section{Corresponding Author:}

Teik Hua Kuan,

Department of Electrical and Electronic Engineering,

Universiti Tunku Abdul Rahman,

Bandar Sungai Long, Cheras 43000, Kajang, Selangor, Malaysia.

Email: thkuan@1utar.my

\section{INTRODUCTION}

NEMA Surge Protection Institute [1] explains surge as an unwanted transient wave of current, voltage or power in an electric circuit. In fact, a surge is simply a brief overvoltage of spikes or disturbances on an electrical circuit. BEAMA [2] explains surge or a transient overvoltage is a short duration increase in voltage measured between two or more conductors. A surge could reach thousands of volts in amplitudes, be positive or negative in polarity, additive or subtractive from the normal current/voltage waveform, generally is oscillatory, decaying over time and measured in microseconds. Surge can cause catastrophic failure or degrade of electronic equipment. Catastrophic failure means permanent equipment/component damaged while degradation means the lifetime of service component is shortened or failed prematurely. Figure 1 shows the catastrophe failure, safe and degradation zone when a system is subjected to surge. The sine wave curve is representing the ac systems and the square wave is representing digital systems. For a typical $230 \mathrm{Vac} 50 \mathrm{~Hz}$ supply, the transient surge superimposed from lightning or switching of heavy load could present for a few $\mu$ s, compared to the $20 \mathrm{~ms}$ ac cycle period as shown in Figure 2 . If the transient amplitude is between 400-600V, the basic circuit blocks are safe (safe zone). When the surge amplitude is within $600-900 \mathrm{~V}$, component degradation will take place or temporary errors could be expected (degradation zone), while values above $900 \mathrm{~V}$ can cause permanent faults (catastrophe failure zone). To protect equipment from catastrophic and degradation failure surge protection device (SPD) is used. Lightning and surges can enter to the system via resistive, inductive and capacitive coupling [3]. 


\section{Transient Anomalies}

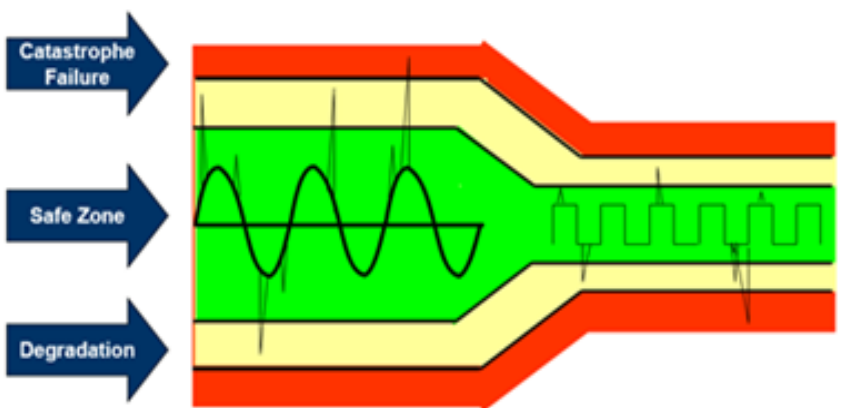

Figure 1. Catastrophe failure, safe and degradation zone when a system is subject to surge [4]

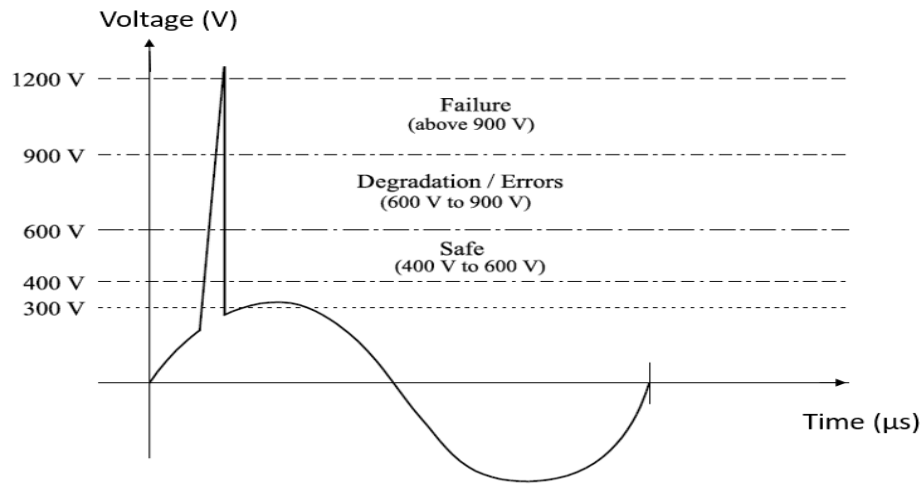

Figure 2. Transient superimposed on the AC-input waveform with its effects

This paper first discusses the working principle of an SPD as a finished product then moves on to look at the individual component used inside the SPD and its technical behavior. For that purpose, two experiments will be evaluated and analyzed. The first experiment evaluates and analyzes the behavior of the SPD as a finished product when subject to surge; the second experiment is to look into the voltage-current (V-I) characteristic of the metal oxide varistor (MOV), one of the important component used inside the SPD.

\section{SURGE PROTECTION DEVICE}

To protect electrical or electronics equipment against the surge, SPD is used. Figure 3 describes the working principle of the SPD for the signal line. When no surge, the SPD will be transparent to the circuit. Once the surge appears, the SPD will spring into action by limiting the output voltage to a predetermined level and divert excessive current to ground to prevent and protect equipment damage.

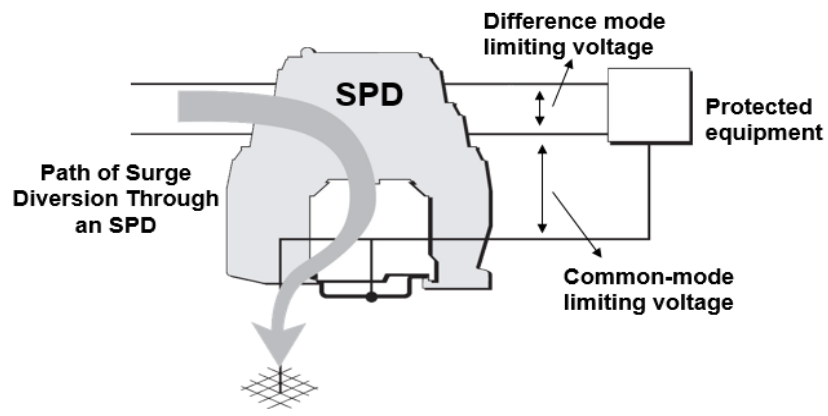

Figure 3. Working principle of SPD [5] 


\subsection{Surge protection components}

All electrical and electronic equipment is designed to operate at a specified nominal voltage with an upper and lower limit. Voltage applies beyond the specified limit will cause the equipment to either damaged or not functioning. A reputable equipment manufacturer will build its product that can handle some voltage variation known as surge withstanding capability (SWC). As long as the surge does not exceed the SWC, the equipment will survive when subject to surges. More information on SWC can be found on IEEE Standard C37.90.1-2002 and [6-8]. Some industry-standard also states the requirement, for example, all galvanic isolated signal converter uses the Oil and Gas industry required the isolator to be able to withstand $1.5 \mathrm{KV}$ (IEC 60079-11); CBEMA curve [9] shows that voltage transients of $200 \%$ from the nominal value is acceptable for $1 \mathrm{~ms}$ for computer and business equipment. SPD works based on the principle of impedance division to limit the voltage and current at the downstream to protect load (vulnerable device) as shown in Figure 4.

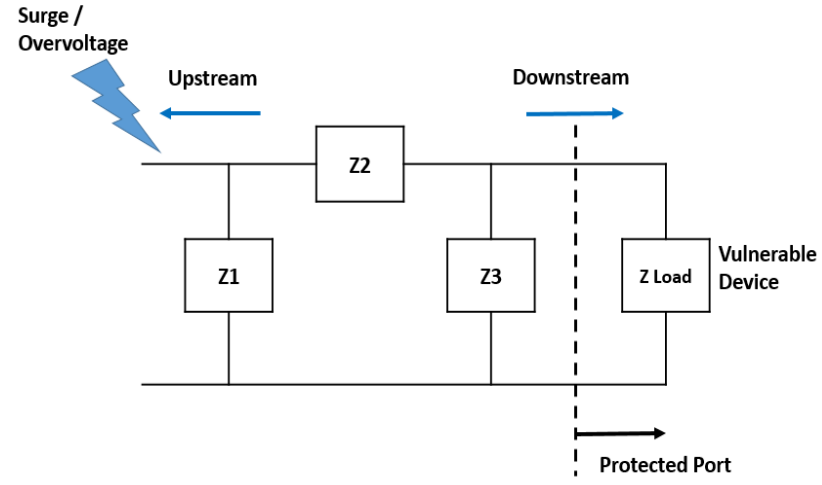

Figure 4. General overvoltage suppression circuit $[10,11]$

The series impedance $\mathrm{Z} 2$ limits the surge current. This series impedance is usually a resistor and inductor [10, 12-13] where during normal operation it has low impedance so that signal is not attenuated. When surge appears, it will be at high impedance due to the high surge frequency and parasitic inductance and capacitance $[12,13]$. The parallel or shunt impedance $\mathrm{Z} 1$ and $\mathrm{Z} 3$ is to divert the surge current away from the load, Z Load and clamp the output voltage to protect the connected load, Z Load. Z1 and Z3 need to be a nonlinear component such as gas discharge tube (GDT), MOV, SAD or silicon control rectifier (SCR). The nonlinear component will be at high impedance (opened circuit) when no surge, goes to low impedance when surge appear. In short, Z1, Z2 and Z3 will be transparent to the circuit under normal operation. Once the surge appears, it will spring into action by limiting the output voltage to a predetermined level and divert excessive current to prevent and protect equipment damage. Depending on the application, SPD could be designed with only $\mathrm{Z} 1$ or $\mathrm{Z3}$, the combination of $\mathrm{Z} 1, \mathrm{Z} 2$ and $\mathrm{Z3}$ or redundancy design. Table 1 provides the possible surge protection component/s for Z1, Z2 and Z3. Individual surge protection components for Z1, Z2 and $\mathrm{Z} 3$ will be explained in detail in the following sections.

Table 1. Component for Z1, Z2 and Z3

\begin{tabular}{ccc}
\hline Z1 & Z2 & Z3 \\
\hline GDT & Resistor (R) & SAD \\
MOV & & Thyristor surge protection device (TSPD) \\
\hline
\end{tabular}

\subsubsection{Resistor}

Resister is normally used as series impedance (Z2) inserted between Z1 (example: GDT) and Z3 (example: SAD) as shown in Figure 4 for multistage designed SPD. An ideal resistor has a constant impedance across all frequencies as shown in Figure 5. However, in practice, any resistor will have parasitic inductance due to the leads and capacitance due to the end caps as shown in Figure 6. Typical parasitic values for 1/4-inch leads carbon-composition resistor provided by [14] is $14 \mathrm{nH}$ of series inductance and $1-2 \mathrm{pF}$ parallel capacitance. 
Figure 7 shows that at low frequency, the resistor behaves as a pure resistor. As the frequency increase, it becomes a capacitor. If the frequency is further increasing than the inductance will dominate the circuit function. In [15] has carried out experiments to measure the parasitic capacitance and inductance of a resistor, the result is tally with the finding of [14]. Internal series resistor for a typical 24Vdc SPD, for 4 to 20 $\mathrm{mA}$ application taken from [16] is 2.2 Ohms per line. This resistance is very low so that during normal operation, the signal drop due to the series impedance is negligible. However, when high-frequency surge appears, the impedance will go high to limit the surge current to the protected load. The series impedance, the industrial termed it as decoupling inductance.

\subsubsection{Metal oxide varistor}

Commercially available MOV consists of a bulk semiconductor material which is mainly made of zinc oxide $(\mathrm{ZnO})$ that can conduct large currents with highly nonlinear voltage-current characteristics like back to back Zener Diode $[17,18]$ as shown in Figure 8 when presented with a voltage above its rated value. However, MOV has a much higher surge handling capacity compare to back to back Zener Diode. The construction of MOV and its characteristic curve in the log-log scale are shown in Figure 9. MOV is a symmetrical bipolar device where it clamps both positive and negative voltages. It also shows that the voltage as an independent variable and current as of the dependent variable. That means it has approximate constant voltage over a wide range of current, a behavior of voltage regulator. MOVs typically limit voltages to about 3 to 4 times the normal circuit voltage by diverting surge current to protect the load [11]. Mulitple MOVs may be connected in parallel to increase current handling capability and life expectancy, provided they have matched sets. Unmatched MOVs have a tolerance of approximately $\pm 20 \%$ on voltage ratings [11], which will cause the lower-rated MOV to carry the higher load (surge current) which eventually breakdown first.
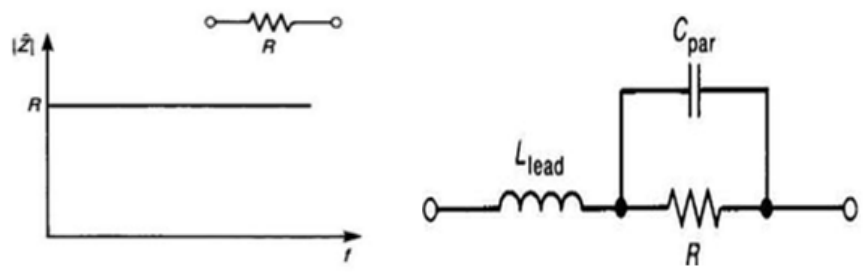

Figure 5. The impedance of an ideal resistor [14]
Figure 6. Real resistor model at high frequencies [14]

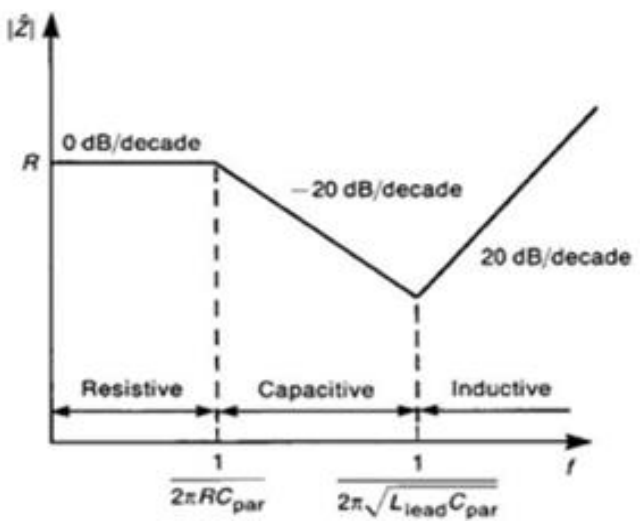

Figure 7. Impedance plot of a real

\section{resistor [14]}

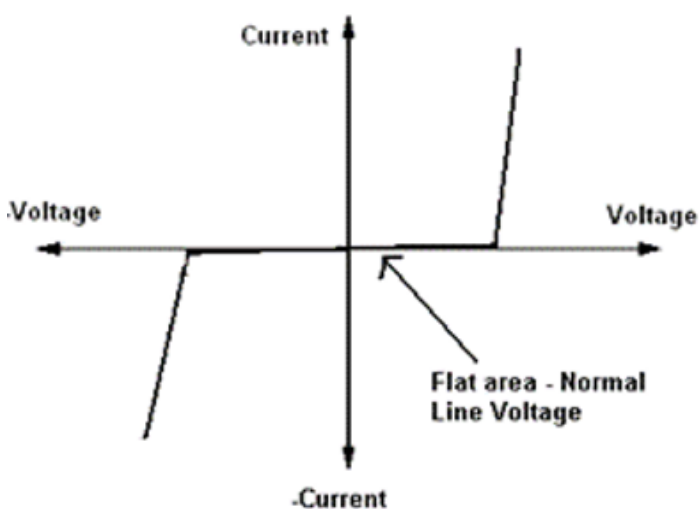

Figure 8. MOV voltage-current characteristic curve 
A basic MOV can be model by components like inductor, capacitor and resistors as shown in Figure 10 and can be represented by (1) [10] and (2) [20]:

$$
\begin{aligned}
& \mathrm{I}=\mathrm{kV} \alpha \\
& \log (\mathrm{u})=\mathrm{B} 1+\mathrm{B} 2 \log (\mathrm{i})+\mathrm{B} 3 \exp (-\log (\mathrm{i}))+\mathrm{B} 4 \exp (\log (\mathrm{i}))
\end{aligned}
$$

where: $V=$ Voltage across the ideal varistor $R_{L}$, not include voltage across $R_{B}$ $\mathrm{I}=$ Current through the ideal varistor, not include the current through $\mathrm{R}_{\mathrm{B}}$ $\mathrm{K}=$ Constant with value normally less than 10-100

$\mathrm{i}=$ Current through the varistor, $\mathrm{R}_{\mathrm{I}}$ $\mathrm{u}=$ Voltage across the varistor, $\mathrm{R}_{\mathrm{I}}$

B1, B2, B3 and B4=Unique for each varistor type obtained from MOV manufacturer datasheet $\alpha$ is the value that causes (1) to be nonlinear. It will determine the performance of the MOV. The greater the $\alpha$ value, the better the MOV performance. A normal resistor will have the value of $\alpha=1$. MOV will have a typical value of $\alpha$ is between 25 and 60 .

MOVs have a finite life expectancy and degrade gradually when subject to a large surge or multiple smaller surge strikes due to the heating of the MOV. The heat generated if not cool down before the next surge will significantly reduce its performance and degraded. As the MOV degrades, its triggering voltage falls lower and lower, effectively reduce the protection level. Generally, only a small leakage current will flow through the MOV when it is not conducting. This small leakage current will not create a fire hazard. However, if the MOV is conducted due to high voltage, a larger current will flow through the MOV which will heat up very quickly. If it is not controlled, it can cause a fire hazard. Figure 11 provides information on selected MOV when 100A to 300A current flowing through it [21]. When the current flowing through the MOV exceeds 100A, the MOV will heat up quickly which can cause a fire hazard. Therefore it is necessary to include some kind of protective mechanism (thermal fuse or thermal disconnect) when designing SPD with MOV to avoid the fire hazard. The disconnect mechanism needs to open the circuit before the MOV catches fire. Figure 12 shows some of the commercially used disconnect mechanism [21].

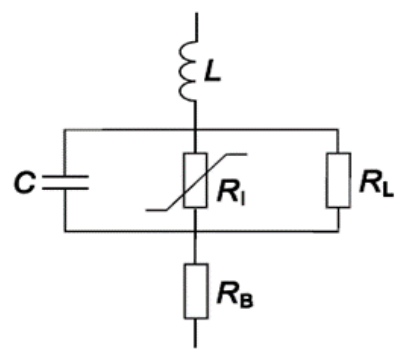

where; $\mathrm{L}=$ Inductance of the conducting leads

$\mathrm{C}=$ Capacitance of the device package zinc oxide material

$\mathrm{R}_{\mathrm{L}}=$ Resistance when MOV at low current

$\mathrm{R}_{\mathrm{B}}=$ Resistance when MOV conduct large currents

$\mathrm{R}_{\mathrm{I}}=\mathrm{Ideal}$ varistor property represented by nonlinear (1)

Figure 10. Equivalent circuit model of a MOV

AC Power Supply SPD

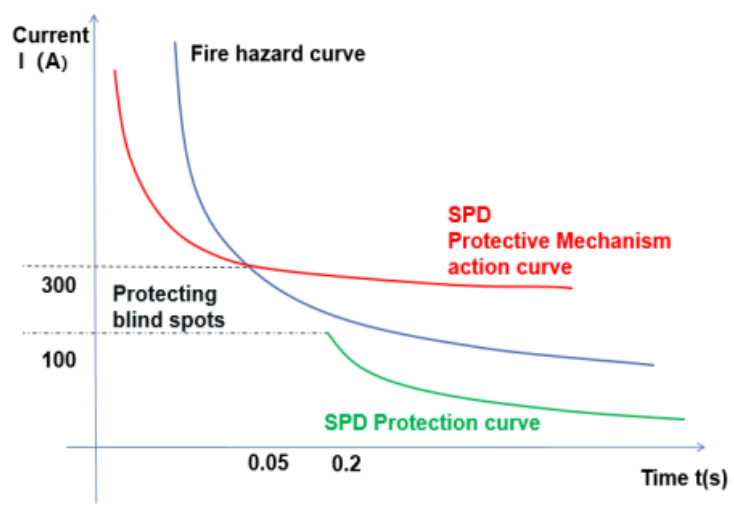

Figure 11. AC SPD short circuit current handling requirement [21]
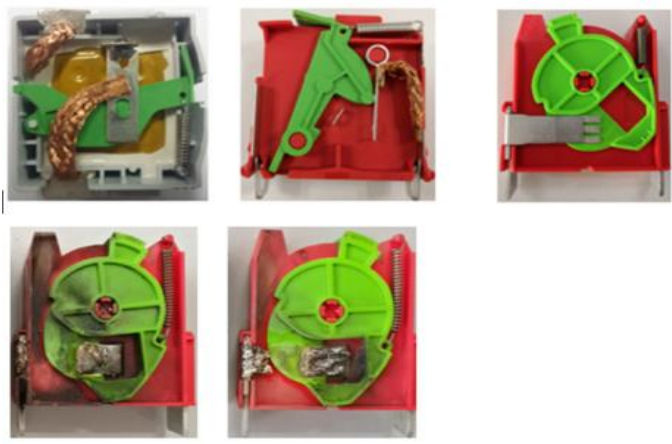

Figure 12. Commercially available thermal disconnect mechanism [21] 
Some of the industrial applications on SPD require knowing its common failure modes, such as the oil and gas industry or the nuclear plant where the MOV is used inside the SPD to protect the process loop which connected to emergency shutdown system (ESD). ESD needs to detect critical loop failure to shut down the plant according to the pre-determined steps to avoid plant explosion or accident. Common failure mode also used to determine the safety integrity level (SIL) of the system design. When MOVs subjected to multiple surge current, it will be degraded causing the $\mathrm{V}_{\mathrm{N}}$ (nominal conduction voltage) to reduce and hence the leakage current increases. If this continues, the MOV will fail with low resistance (short circuit).

\subsubsection{Gas discharge tube}

GDT is made up of two or more metal electrodes which are separated by a glass or ceramic cylinder filled with a noble gas mixture such as neon, argon, etc. which conduct electric current after becoming ionized by a high voltage spike. As GDT is filled with this internal gas, when it is fired it will require time to ionize. The GDT can take several microseconds to turn on depending on the slope of the transient front. Generally, a circuit protected by GDT will see overshoot voltages ranging from a few hundred volts to several thousand volts. GDT is a bipolar device with no polarity sensitive. Like MOVs, GDTs have a finite life expectancy and can handle large transients. The basic operation of GDT can be illustrated by referring to Figure 13 and divides them into regions. It can also be simplified as per Figure 14.

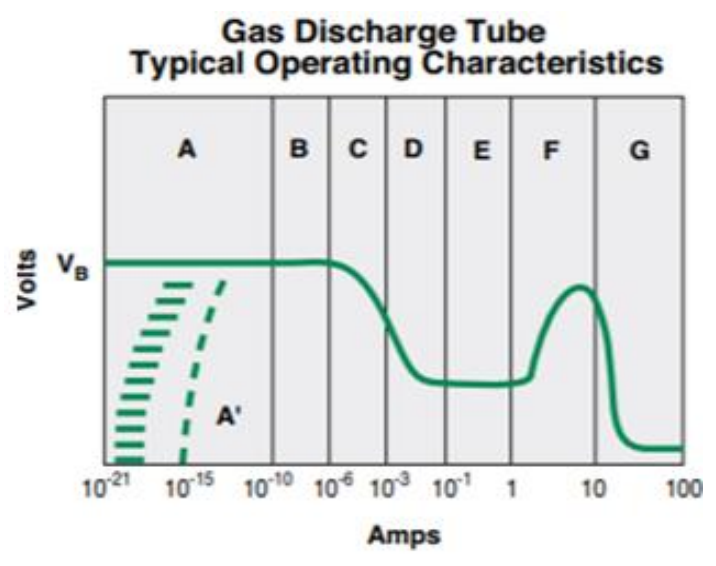

Figure 13. Voltage-current relationship of the GDT and its typical operating characteristics [22]

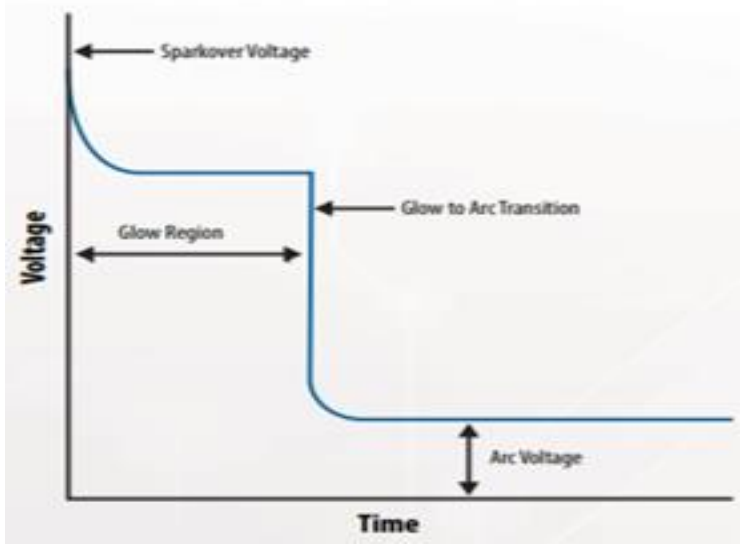

Figure 14. GDT voltage breakdown characteristic [23]

GDT can be view as a voltage-dependent switch with effective arc discharge. GDT maintains a high impedance during off stage and low impedance when applied voltage above the breakdown voltage which causes it to turn on. During arc-over, the GDT exhibits the low impedance of a crowbar device resulting in very low on-stage voltage (arc voltage). The crowbar effect of the GDT effectively limits the overvoltage to a low level and shunts the associated follow current away from downstream components and circuitry. When the surge event subsides and the system voltage returns to normal levels, the GDT will reset into its high impedance (off) stage. The common failure mode of GDT is an increase in breakdown voltage at which the GDT conducts or increases it let-through voltage. Hence the protection decreases over a long period when surge current above its rating.

\subsubsection{Surge avalanche diode (SAD)}

$\mathrm{SAD}$ is also known as transient voltage suppression (TVS) diode that can limit voltage spikes. It is designed to breakdown and conduct at a well-defined reverse voltage without being damaged. SAD is intended to operate in the reverse breakdown region as shown in Figure 15. Thus, SADs are often used in protecting circuits against transient voltages which otherwise would damage the circuit. SAD has the smallest value of $\mathrm{dV} / \mathrm{dI}$, offered the tightest voltage clamping which makes it the most preferred final stage of protection circuit on multistage protection. SAD also provides the fastest limiting action of protective components in picoseconds [11] but has a relatively low energy absorbing capability. For example, SAD with a die area of $10 \mathrm{~mm}^{2}$ is able to withstand a surge with reverse voltage and current of 1200V 75A [24]. Due to their relatively limited current capacity, SADs are often used in the circuits with smaller current spikes.

SAD does not degrade when operating at its rated value. If the current pass through the SAD is within its rated value, life expectancy is exceptionally long. If the rated value exceeded, the diode may fail as 
a permanent short circuit. In this case, protection may remain but normal circuit operation terminated as the signal line shorted. However, if the surge current is too high, it can rupture its epoxy package. Therefore, when the application required SIL rated or detectable failure mode (short circuit), then the hermetically sealed metal package should be used.

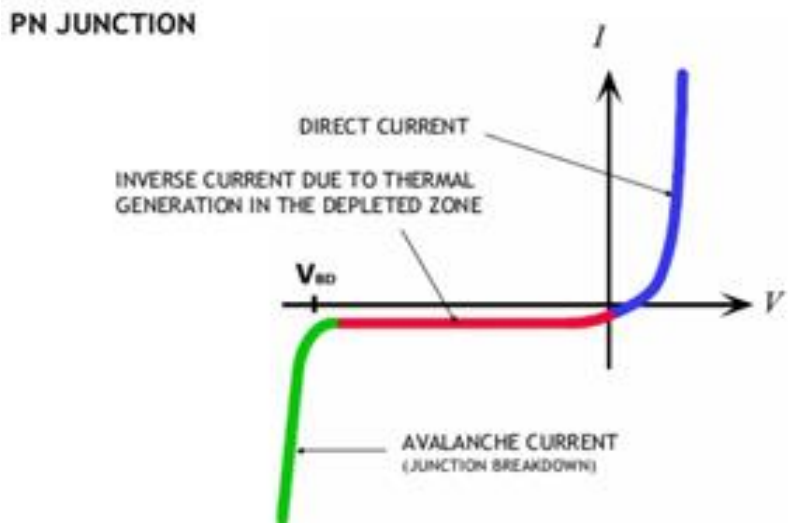

Figure 15. V-I relationship of SAD, operate at reverse breakdown region

\subsubsection{Thyristor surge protection device}

TSPD is a specialized solid-state electronic avalanche-triggered component. It protects circuits with a high current crowbar effect by switching to a low on-state voltage. They are available in bidirectional or unidirectional configurations. The TSPD is transparent to the circuit until a surge is present. It has low off-state leakage current (few microamperes), high breakdown voltage, and negligible capacitance that have no effect on normal circuit performance [25]. Once the TSPD is in on-state conduction, the current running through the device must be interrupted, or drop below the minimum holding current, to restore to non-conduction state after the transient has subsided. This is the typical characteristic of most of the SCR. The voltage-current characteristic of TSPD is described in Figure 16.

\begin{tabular}{|l|l|}
\hline Symbol & Parameter \\
\hline$I_{D 1}, I_{D 2}$ & Off State Leakage Current \\
\hline$V_{D 1}, V_{D 2}$ & Off State Blocking Voltage \\
\hline$V_{B R}$ & Breakdown Voltage \\
\hline$V_{B O}$ & Breakover Voltage \\
\hline$I_{B O}$ & Breakover Current \\
\hline$I_{H}$ & Holding Current \\
\hline$V_{T M}$ & On State Voltage \\
\hline
\end{tabular}

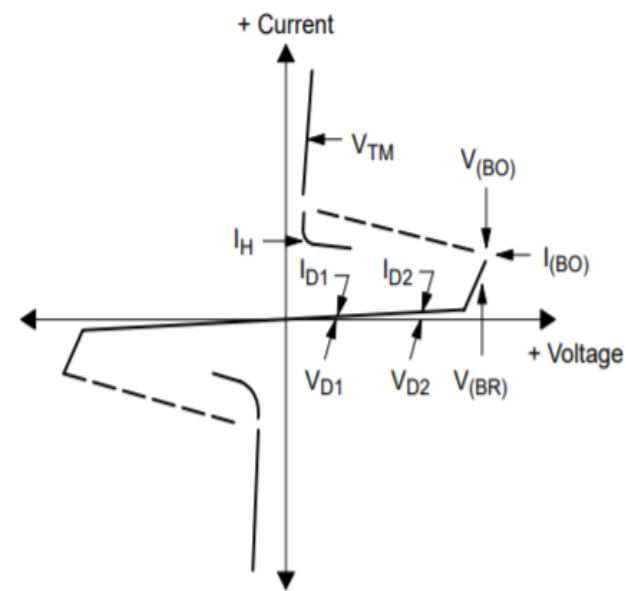

Figure 16. Voltage-current characteristic of TSPD (bidirectional device) [25]

TSPDs are normally not used for protection across dc power or low-impedance voltage sources because after switching to on-state, they may not restore to non-conduction. SAD is the best choice for dc applications. The major advantages of the TSPD are its high surge current rating compare to SAD, low on-state crowbar voltage, and low capacitance. TSPD does not degrade when operating at its rated value. If the current pass through the TSPD is within its rated value, life expectancy is exceptionally long. TSPD is a fail-safe component, meaning when overstressed, it will fail to short circuit preventing continued unprotected operation [25]. 


\subsection{Summary of various SPD components}

To design an effective SPD, depending on the application, various SPD components are used. Table 2 provides a summary of the various SPD components suitable for Z1 and Z3 shown in Figure 4 as well as the advantages, disadvantages, technology and expected lifetime on various SPD components.

Table 2. Advantages, disadvantages, technology and expected Life of SPD components [10]

\begin{tabular}{|c|c|c|c|c|}
\hline $\begin{array}{c}\text { SPD } \\
\text { Component }\end{array}$ & Advantages & Disadvantages & Technology & Expected Life \\
\hline \multirow{5}{*}{ MOV } & Fast response $(<0.5 \mathrm{~ns})$ & Gradual degradation & \multirow{5}{*}{ Clamps } & \multirow{5}{*}{ Degrades } \\
\hline & Can safely conduct large currents $(1 \mathrm{kA}$ & High clamping voltage & & \\
\hline & & High parasitic capacitance ( 1 to & & \\
\hline & Large energy absorption & $10 \mathrm{nF})$ & & \\
\hline & Inexpensive & & & \\
\hline \multirow{5}{*}{ GDT } & Slow response times & High firing voltage $\geq 100 \mathrm{~V}$ & \multirow{5}{*}{ Crowbars } & \multirow{5}{*}{ Limited } \\
\hline & $\begin{array}{l}\text { Can safely conduct large currents ( } 5 \mathrm{kA} \\
\text { for } 50 \mu \mathrm{s} \text { ) }\end{array}$ & Finite life cycle & & \\
\hline & Low parasitic capacitance $(<2 \mathrm{pF})$ & Slow response times & & \\
\hline & High insulation resistance & Non-restoring under DC & & \\
\hline & Low voltage in arc mode & $\begin{array}{l}\text { Possible "follow current" (sustained } \\
\text { short circuit) }\end{array}$ & & \\
\hline \multirow{3}{*}{ SAD } & Extremely fast response time $(<0.1 \mathrm{~ns})$ & $\begin{array}{l}\text { Limited surge current rating }(\leq 100 \mathrm{~A} \\
\text { for } 100 \mu \mathrm{s})\end{array}$ & \multirow{3}{*}{ Clamps } & \multirow{3}{*}{ Long } \\
\hline & $\begin{array}{l}\text { Precise selection on clamping voltage } \\
(6.8 \mathrm{~V} \text { to } 200 \mathrm{~V})\end{array}$ & High parasitic capacitance ( 1 to $3 \mathrm{nF}$ ) & & \\
\hline & Does not degrade & & & \\
\hline \multirow{3}{*}{ TSPD } & Moderate fast response time & Non-restoring under DC & \multirow{3}{*}{ Crowbars } & \multirow{3}{*}{ Long } \\
\hline & High current-handling capability & Narrow voltage range & & \\
\hline & Does not degrade & Turn-off delay time & & \\
\hline
\end{tabular}

\section{RESEARCH METHOD}

Two experiments will be evaluated and analyzed. The first experiment evaluates and analyzes the behavior of the SPD as a finished product when subject to surge; the second experiment is to look into the voltage-current (V-I) characteristic of the MOV.

\subsection{Experiment 1: Performance evaluation and analysis of SPD}

Industrial application SPD normally come in multistage protection design as per Figure 17. A typical example will be the SD32X model from Eaton Electrical. All three impedances, Z1, Z2 and Z3 are present for this design, namely: Z1 is the GDT, Z2 is resistor and Z3 is SAD.
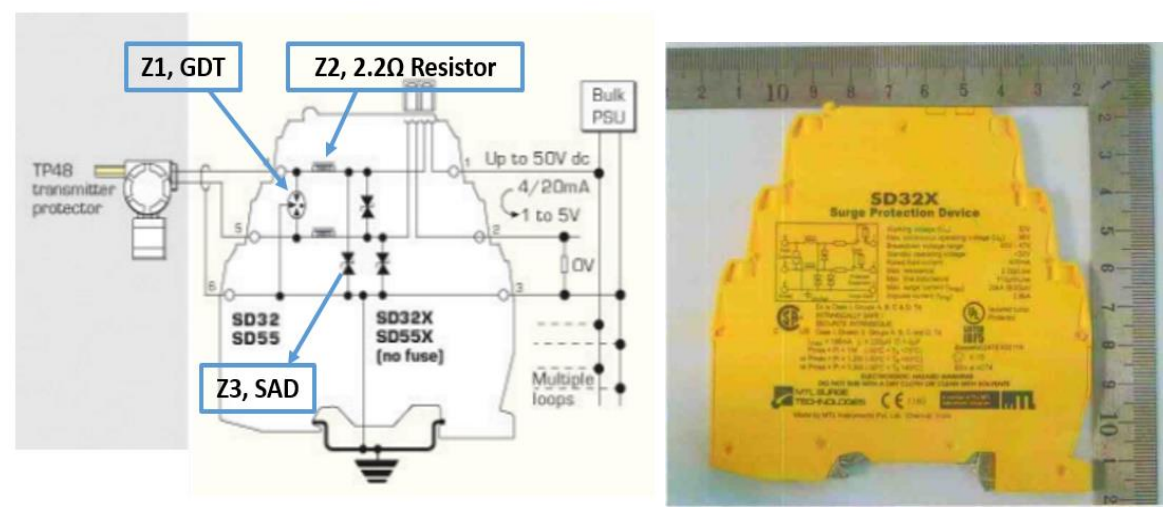

Figure 17. Commercial SPD; model SD32x from Eaton Electrical Inc. [16]

Test Conditions:

a. Model: SD32X manufactured by Eaton Electrical Inc.

b. Ambient Temperature: $25^{\circ} \mathrm{C}$ (air-condition room)

c. Relative Humidity $65 \%$

d. $1.2 / 50 \mu \mathrm{s}$ open circuit voltage waveform and $8 / 20 \mu \mathrm{s}$ short circuit current waveform according to IEC 6100-4-5 
Key specification on SD32X

a. Nominal Voltage: $32 \mathrm{Vdc}$; Series resistance per line: $2.2 \mathrm{Ohms}$

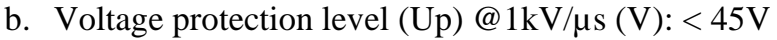

Equipment:

a. Combine Wave Generator as per IEC 6100-4-5 is used. Equipment model: SUG61005TB manufactured by Shanghai Prima Electronics Co., Ltd. Source Resistance: 2 Ohms

b. Digital Oscilloscope, Model: Tektronix TDS5104

c. Current transformer and differential probe

A surge generated by Combine Wave Generator with an open circuit voltage of $6 \mathrm{kV}$ (Uoc=6kV) @ $1.2 / 50 \mu \mathrm{s}$ is injected into the SPD SD32X. Both positive and negative pulse is injected into the SD32X. Digital Oscilloscope is used to capture the waveform of the surge and the output voltage response of the SPD SD32X.

\subsection{Experiment 2: MOV V-I characteristic measurement}

$\mathrm{V}$-I characteristics of a MOV is one of its most important parameters. Its characteristics are summarized in Figure 18. Experiment 2 is to evaluate and analyze the MOV behavior at clamping region and the leakage/low current region.

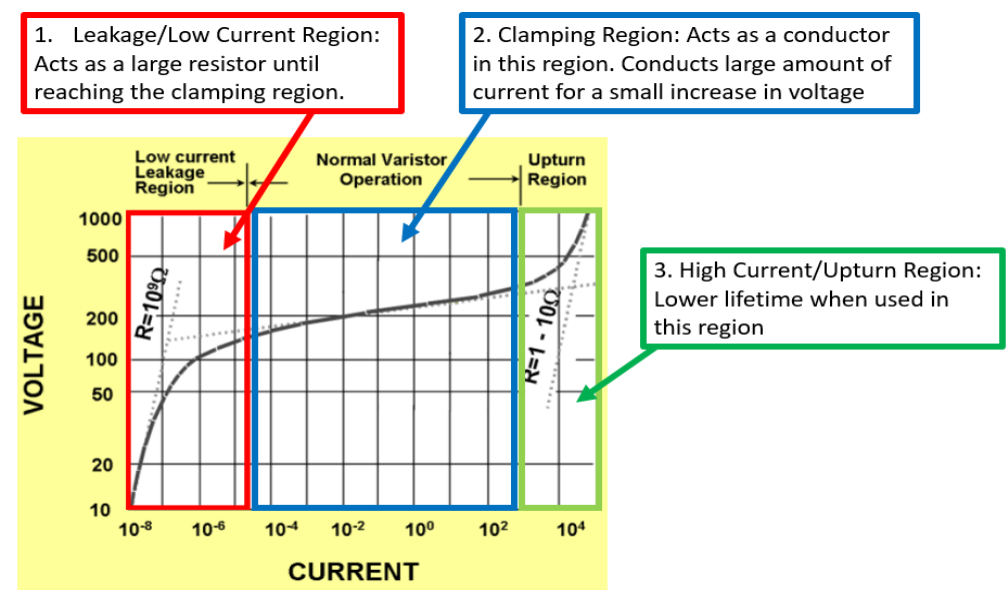

Figure 18. V-I characteristics curve of a MOV

\subsubsection{MOV behavior at clamping region}

The circuit as in Figure 19 is set up to measure the voltage and current at the clamping region of the MOV. For this experiment, Littelfuse MOV 275L40C (C-III Series), 20V275 (UltraMOV Series) and V271HA32 (Industrial High Energy Terminal Varistors HA Series) are selected. All the selected MOVs are rated at a maximum of $275 \mathrm{~V}$.
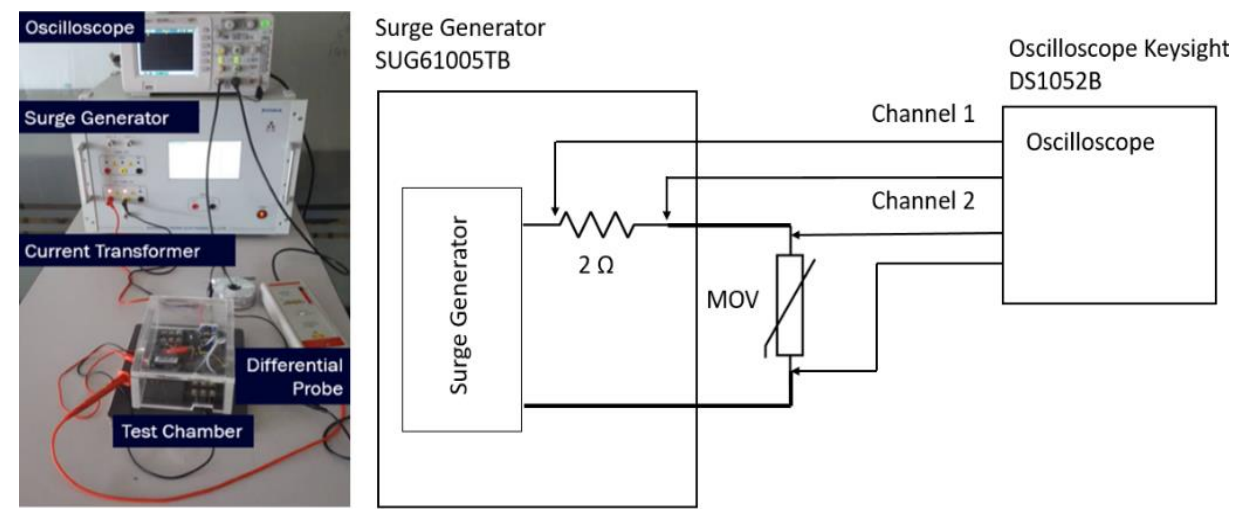

Figure 19. MOV voltage and current measurement setup with $2 \mathrm{ohms}$ source resistance

Bulletin of Electr Eng \& Inf, Vol. 10, No. 1, February 2021 : 10 - 22 
Equipment:

a. Combine Wave Generator; Model: SUG61005TB manufactured by Shanghai Prima Electronics Co., Ltd. Source Resistance: 2 Ohms

b. Keysight Oscilloscope; Model: DS1052B

c. Littelfuse MOV Radial Lead Varistor

Model: 275L40C (C-III Series), 20V275 (UltraMOV Series) and V271HA32 (Industrial High Energy Terminal Varistors HA Series).

A combination wave generated by Surge Generator SUG61005TB with $1.2 / 50 \mu$ s open circuit voltage waveform and $8 / 20 \mu \mathrm{s}$ short circuit current waveform is injected into the MOV. Oscilloscope Keysight DS1052B is used to measure the voltage and current value. A series of surge pulses with different voltage amplitudes were applied to each of the MOV in steps of $100 \mathrm{~V}$, from $0.1 \mathrm{kV}$ to $6.0 \mathrm{kV}$.

\subsubsection{MOV behavior at the leakage/low current region}

Another important parameter to measure will be the leakage current $\left(\mathrm{I}_{\mathrm{MOV}}\right)$ when the MOV operating at leakage/low current region as shown in Figure 18. This current should be below $1 \mathrm{~mA}$. Hence, it is not possible to measure the $\mathrm{I}_{\mathrm{MOV}}$ with the same set up as per Figure 19. To measure the leakage current $\mathrm{I}_{\mathrm{MOV}}$, the circuit in Figure 20 is used, a DC source is used instead of a surge generator.
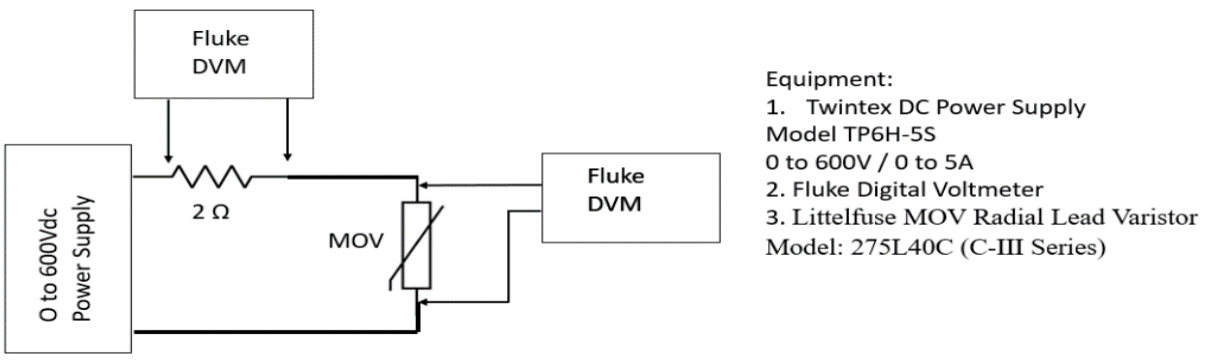

Figure 20. Setup for measuring MOV voltage and current in the off stage

\section{RESULTS AND DISCUSION}

\subsection{Performance evaluation and analysis of SPD}

The obtained waveform is shown in Figure 21 (only positive pulse is presented) and the data for both positive and negative pulse are tabulated in Table 3. Figure 21 shows the SPD SD32X is clamping down the surge voltage from $6 \mathrm{kV}$ to $46.8 \mathrm{~V}$. The clamped down voltage is also known as "Let-Through" voltage in the industry. The clamping voltage $(46.8 \mathrm{~V})$ is close to the data provided by the SPD manufacturer $(45 \mathrm{~V})$. Equipment or device with SWC above $46.8 \mathrm{~V}$, when connected to the downstream of the SPD, will be protected. The SPD is performed as per claim by the manufacturer datasheet. Based on the result of the experiment, for effective equipment protection, the let-through voltage of the SPD must be lower than the SWC of the equipment that needs to be protected. This will be one of the SPD selection criteria.

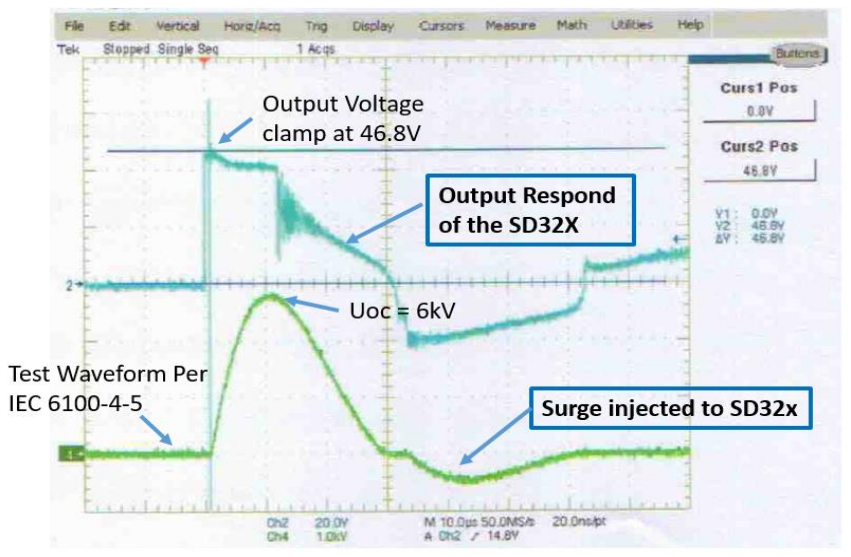

Figure 21. Test result on Eaton SD32X SPD 
Table 3. Injected current and output voltage of SD32X

\begin{tabular}{cccccc}
\hline \multicolumn{5}{c}{ Uoc $=6 \mathrm{kV}$} \\
\hline $\begin{array}{c}\text { Ve } \\
\text { Pulse/No. }\end{array}$ & $\begin{array}{c}\text { Injected } \\
\text { Current (kA) }\end{array}$ & $\begin{array}{c}\text { Output } \\
\text { Voltage (V) }\end{array}$ & $\begin{array}{c}- \text { Ve } \\
\text { Pulse/No. }\end{array}$ & $\begin{array}{c}\text { Injected } \\
\text { Current (kA) }\end{array}$ & $\begin{array}{c}\text { Output } \\
\text { Voltage (V) }\end{array}$ \\
\hline 1 & 2.90 & 46.8 & 1 & -2.9 & -47.6 \\
2 & 2.90 & 46.0 & 2 & -2.9 & -48.4 \\
3 & 2.89 & 46.8 & 3 & -2.9 & -47.6 \\
4 & 2.89 & 46.8 & 4 & -2.9 & -48.0 \\
5 & 2.90 & 46.8 & 5 & -2.9 & -48.0 \\
\hline
\end{tabular}

\subsection{MOV V-I characteristic measurement}

It is observed that all MOVs operate in off stage for the surge pulses ranging from 100 to $500 \mathrm{~V}$ and all MOVs turn on when the surge pulse beyond $600 \mathrm{~V}$. For the pulses above $600 \mathrm{~V}$ to $6 \mathrm{kV}$, the MOVs managed to clamp down the voltage to slightly above $600 \mathrm{~V}$. Voltage and current waveform for MOV 275L 40C is presented in Figure 22 when the surge generator is set to $700 \mathrm{~V}$. From Figure 22, it is observed that the voltage peak occurs before the current peak. The same observation happens to 20V275 and V271HA32. This means that the MOV during conduction is not purely resistive. It actually contains reactive components. This also explained the reason inductor and capacitor are included in MOV equivalent circuit given in Figure 10.

The data is tabulated in Table 4 and the V-I curve is plot per Figure 23. The MOV voltage at $1 \mathrm{~mA}$ DC test current specified in the manufacturer datasheet is ranging from $389 \mathrm{~V}$ to $473 \mathrm{~V}$. The data provide in Table 4 and Figure 23 confirms this. From Table 4 and Figure 23, it is observed that the impedance changes from $680 \mathrm{M} \Omega$ during OFF stage to $6.7 \Omega$ during $\mathrm{ON}$ stage at $700 \mathrm{~V}$ pulse. From the impedance data, when MOV is used as shut impedance when no surge it will be transparent (open circuit) to the circuit (very low leakage current); when surge appears, it will act as a switch (short circuit) to divert the surge current (can conduct high current). By using the set up in Figure 23 (DC source) and Figure 20 (surge impulse), $\mathrm{V}_{\text {MOV }}$ and $\mathrm{I}_{\mathrm{MOV}}$ are obtained.

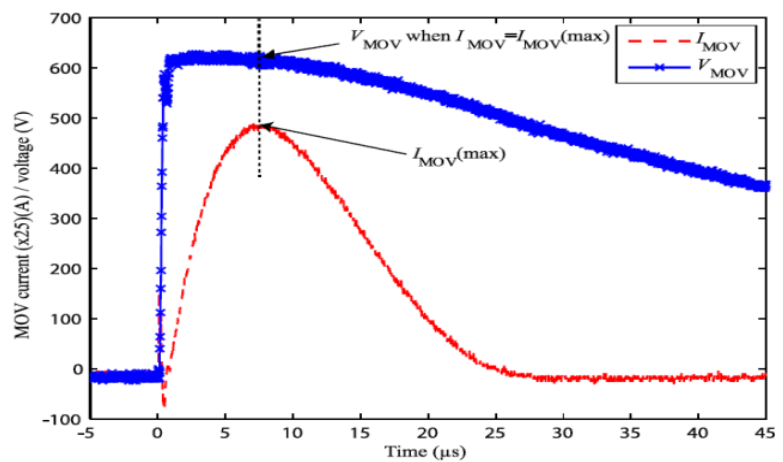

Table 4. IMOv readings when voltage below and

\begin{tabular}{cccc}
\multicolumn{4}{c}{ above $\mathrm{V}_{\mathrm{N}}$ for 275L40C } \\
\hline Source & $\mathrm{V}_{\mathrm{MOV}}(\mathrm{V})$ & $\mathrm{I}_{\mathrm{MOV}}(\mathrm{A})$ & Impedance $(\Omega)$ \\
\hline DC & 100 & $1.48 \mathrm{E}-07$ & $676 \mathrm{M}$ \\
DC & 200 & $1.11 \mathrm{E}-06$ & $180 \mathrm{M}$ \\
DC & 300 & $8.78 \mathrm{E}-06$ & $34 \mathrm{M}$ \\
DC & 400 & $4.10 \mathrm{E}-05$ & $10 \mathrm{M}$ \\
DC & 450 & $1.89 \mathrm{E}-03$ & $238 \mathrm{~K}$ \\
DC & 500 & 2 & 250.00 \\
Impulse & 600 & 5 & 120.00 \\
Impulse & 640 & 23 & 27.83 \\
Impulse & 680 & 74 & 9.19 \\
Impulse & 700 & 105 & 6.67 \\
\hline
\end{tabular}

Figure 22. Voltage and current waveform measured across and through the MOV when the surge generator set to $700 \mathrm{~V}$ for MOV 275L40C

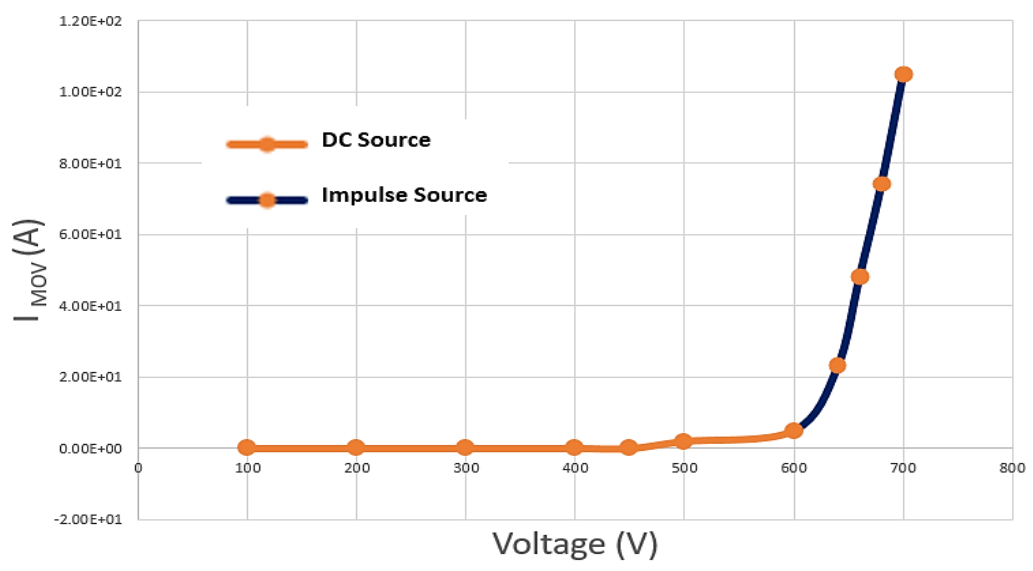

Figure 23. V-I plots for MOV 275L40C

Bulletin of Electr Eng \& Inf, Vol. 10, No. 1, February 2021 : 10-22 


\section{CONCLUSION}

SPD is transparent to the system when no surge. When surge appears, it will limit the output voltage and divert the surge current away. SPD using impedance divider principle by coordinating series and parallel impedance to divert the surge current away and to bring down the output voltage to a predetermined level to protect the connected load. The resistor at high frequency is no longer a pure resistor due to the parasitic impedance. During surge, the resistor with the parasitic impedance behaves like an inductor blocking the surge current from entering the downstream component. The shut impedance needs to be a nonlinear voltage-current component so that when no surge it is at high impedance (open circuit); when surge appears, it goes to low impedance (short circuit) to shut away the surge current. For MOV, it can be concluded that when operates at clamping region, it is not purely resistive. It actually contains reactive (inductor and capacitor) components as described by MOV equivalent circuit as shown in Figure 10. MOV when operating at the leakage/low current region will have a very high impedance that makes it transparent to the system. For effective surge protection, one of the selection criteria will be the let-through voltage of the SPD, which must be lower than the SWC of the equipment to be protected.

\section{REFERENCES}

[1] NEMA Surge Protection Institute. [Online]. Available: https://www.nemasurge.org/history/. [Accessed: June 08, 2019].

[2] BEAMA, "Guide To Surge Protection Devices (SPDs) Selection, Application and Theory," pp. 1-68, May 2014.

[3] Crouse-Hinds, "Lightning surge protection for electronic equipment - a practical guide," Application note MTL surge protection, Oct-2016. [Online]. Available: https://www.mtl-inst.com/images/uploads/AN_9041001_Rev_G.pdf. [Accessed: 17-Aug-2020].

[4] KL Automation Engineering Sdn Bhd. "Basic on SPD: Catastrophe failure, safe and degradation zone," SPD Training Manual, 2020.

[5] Eaton Electric Limited, "Surge protection for electrical power installations," Application note. MTL surge protection. AN1009 Rev B. [Online]. Available: https://www.mtl-inst.com/images/uploads/AN_1009_Rev_B.pdf. [Accessed: October 2016].

[6] François Martzloff, "Surge Withstand Capability of Various Devices," General Electric Company, Schenectady, NY, pp. 1-10, 2019.

[7] Triconex Products-Invensys Process Systems, "Surge Withstand Test Report," Document No: 9600164-528, pp. 1-44, 30 April 2008.

[8] Ibrahim A. Metwallya, Adel Gastli, and Mohamed Al-Sheikhb, "Withstand capability tests of transient voltage surge suppressors," Electric Power Systems Research, vol. 77, no. 7, pp. 859-864, May 2007.

[9] "Computer and Business Equipment Manufactrers' Association," [Online]. Available: http://www.powerqualityworld.com/2011/04/cbema-curve-power-quality-standard.html, Accessed: June 08, 2019.

[10] Ronald B. Standler, "Protection of Electronic Circuit from Overvoltages," Pennsylvania, Dover Publications Inc, pp. 1-410, 1989.

[11] M. M. Josephine and G. A. Ikechukwu, "Performance of Surge Arrester Installation to Enhance Protection," Advances in Science, Technology and Engineering Systems Journal (ASTESJ), vol. 2, no. 1, pp. 197-205, 2017.

[12] H. Domingos and D. Wunsch, "High Pulse Power Failure of Discrete Resistors," in IEEE Transactions on Parts, Hybrids, and Packaging, vol. 11, no. 3, pp. 225-229, Sep 1975.

[13] D. M. Tasca, D. C. Wunsch and H. Domingos, "Device Degradation by High Amplitude Currents and Response Characteristics of Discrete Resistors," in IEEE Transactions on Nuclear Science, vol. 22, no. 6, pp. 2522-2527, Dec 1975.

[14] K. Wyatt, "Resistors aren't resistors-Kenneth Wyatt," EDN, 29-Oct-2013. [Online]. Available: https://www.edn.com/resistors-arent-resistors/. [Accessed: 04-Apr-2020].

[15] Paul Benjamin Crilly, Tooran Emami, "Resistors, Capacitors and Inductors Are Not as They Appear, " 2018 ASEE Annual Conference \& Exposition, American Society for Engineering Education, pp. 1-11, 24-27 June 2018.

[16] "Technical data MTL surge protection EPS 01-107 Rev V MTL ...," Search Results Web results MTL SD rangeEaton MTL, Jun-2017. [Online]. Available: https:/www.mtl-inst.com/images/uploads/datasheets/901107_Rev_V_SD_130617.pdf. [Accessed: 05-Apr-2020].

[17] Levinson LM, Philipp, H. R, "Zinc oxide varistors-a review," American Ceramic Society Bulletin, vol. 65, no. 4, pp. 639-646, 1986.

[18] Tapan K. Gupta, “Application of zinc oxide varistors," Journal of the American Ceramic Society, vol 73, no. 7, pp. 1817-40, 1990.

[19] J. D. Harnden Jr., F.D. Martzloff, W. G. Morris and F. B. Golden, "Metal-oxide varistor: A new way to suppress transients," Semiconductor Products Department, General Electric Co., 1972.

[20] R. Brocke, T. Goehlsch, F. Noack, "Numerical Simulation of Low-Voltage Protective Devices," International Zürich Symposium on EMC, Zürich, 1993.

[21] Shanghai Chenzhu Instrument Co., Ltd. "SPD for power supply: Short Circuit Handling Capability," SPD Training Manual, 2019.

[22] Littelfuse, Inc., "Gas Discharge Tube (GDT) Products," [Online]. Available: https://m.littelfuse.com/ /media/electronics/product_catalogs/littelfuse_gdt_catalog.pdf.pdf. Accessed: June 08, 2019.

[23] Bourns, Inc., "Gas Discharge Tubes,". [Online]. Available: https://pdf.directindustry.com/pdf/bourns/gas-dischargetubes/11910-335121.html. Accessed: June 08, 2019 
[24] F. Schork, R. Brocke and M. Rock, "Surge current capability of power electronics for surge protection," PCIM Asia 2016; International Exhibition and Conference for Power Electronics, Intelligent Motion, Renewable Energy and Energy Management, Shanghai, China, pp. 1-8, 2016.

[25] “ON Semiconductor MMT05B350T3 Product Review," Manuals Library, May-2006. [Online]. Available: https://www.manualslib.com/manual/834095/On-Semiconductor-Mmt05b350t3.html. [Accessed: 26-Mar-2020].

\section{BIOGRAPHIES OF AUTHORS}
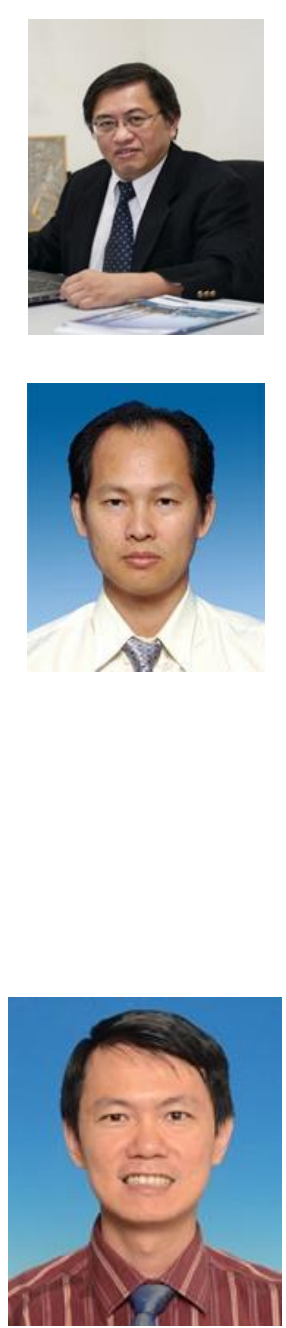

Teik Hua Kuan, Academic Qualification: M. Eng. (Universiti Tunku Abdul Rahman), B. Tech (Hons) (Wawasan Open University), Dip. EE (Nanyang Polytechnic, Singapore), Dip. Sales \& Marketing (National Productivity Board of Singapore), Professional Qualification: Professional Technologist (PT18050181) Experience: More than 30 years of Asia Pacific Regional working experience in the hazardous area instrumentation, SPD and automation components. Ts. Kuan currently is the group director for KL Automation Engineering Group of Companies. He is also a part-time tutor and project supervisor for Wawasan Open University; Final year Industrial Supervisor for basic degree and co-supervisor for master degree at Universiti Tunku Abdul Rahman

Kuew Wai Chew received his B. Sc (Hons) and Ph.D. (Advanced Materials) from Universiti of Malaya (UM) in the year 1999 and 2003. Upon completion of his Ph.D. degree, he joined Multimedia University from 2003 to 2008 as a lecturer. From 2008 to 2012, Dr. Chew is attached to the Department of Electrical and Electronic Engineering, UTAR as an Assistant Professor. Due to his good teaching, research and publications record, Dr. Chew has been promoted to the position of Associate Professor starting from 2013 until to date. Dr. Chew has more than 10 years of research experience covering the area of advanced materials, hybrid energy storage and electric vehicle related research. He has been actively involved in the research activities as a principal investigator or co-researcher. Up to date, he has secured more than 10 internal grants and 4 external research grants. Under Dr. Chew's supervision, 8 postgraduate students have completed their studies. His research interests including of hybrid energy storage systems, electric vehicle distance estimation systems and power electronics converters. Currently, he actively participates in the research area of lighting and surge protection for potentially hazardous areas. Dr. Chew conducts more than 10 consultancy jobs in explosion protection and data center. Currently, he is a Huawei certified trainer for the Data Center. Dr. Chew is currently a senior member for IEEE and Chartered Engineer (CEng) for IET.

Kein Huat Chua obtained his Bachelor of Engineering (Electrical, Electronic and Systems) from Universiti Kebangsaan Malaysia (UKM) in 2004, Master of Engineering (Electrical Energy and Power System) from Universiti Malaya (UM) in 2009 and Ph.D. (Electrical Engineering) from Universiti Tunku Abdul Rahman (UTAR) in 2016. His Ph.D. research area is in energy storage applications for the electrical grid. He is currently working as an Assistant Professor in the Department of Electrical and Electronic Engineering, Lee Kong Chian Faculty of Engineering, UTAR. His research focuses on energy storage systems, energy management systems, energy audit, earthing and lightning protection systems, electrical machines and drives. 